\title{
Hysteresis Current Control Based Shunt Active Power Filter for Six Pulse Ac/Dc Converter
}

\author{
Rakesh Kumar Pandey*, Vaibhav Purwar**, Nikhlesh Sharma*** \\ *Research Scholar, Mewar University, Chittorgarh (RAJ.) \\ ** Assistant Professor, Kanpur Institute of Technology, Kanpur (UP) \\ *** Professor, GL Bajaj Institute of Technology and Management, Greater Noida (UP)
}

\begin{abstract}
In this paper the simulation of Shunt Active power Filter using P-Q theory and PI controller has been presented. This SAPF compensates the harmonic currents drawn by three phase six pulse AC/DC converter. The process of compensation is done by calculating the instantaneous reactive power losses using p-q theory and the PI controller to reduce the ripple voltage of the dc capacitor of the PWM-VSI. This approach is different from conventional approach and provides very effective solution. In this simulation we use hysteresis band current controller (HCC) for switching the VSI inverter. The simulation has been done for both steady state and transient conditions.
\end{abstract}

Keywords: Shunt Active Power Filter (SAPF), proportional integral (PI), Hysteresis Current Controller (HCC), Pulse width modulator-voltage source inverter (PWM-VSI)

\section{INTRODUCTION}

A lot of research has been done on Shunt Active Power Filters and they are applied in many practical applications. The first basic principle of active filter compensation was proposed in 1970, but the actual design of this filter was proposed by Gyugyi and Strycula in 1976[13]. In1983, 1984 a new concept of Instantaneous reactive power theory was introduced by Akagi $[11,12]$.This new concept of Instantaneous reactive power theory was proved to be very useful in Active filter compensation. Peng and Lai Proposed instantaneous power theory in generalized way [9] that is applicable for balanced or unbalanced, sinusoidal or non-sinusoidal; three phase power systems with or without zero-sequence currents. The Harmonics current generated by motor-drives arc furnaces, tap changing transformers, diode, thyristor and GTO converters are matters of serious concern as they cause harmonic interference in transmission, industrial applications, and distribution systems [4, 5]. Active Power Filters are inverter circuits, having active devices such as semiconductor (diodes, thyristor, MOSFET) they can be controlled by the harmonic current or voltage generated by the nonlinear load. Active Power Filters are superior to passive filters because they remove the resonance related problems.

Active Power Filter improves the power quality of ac source and removes the harmonics from the source current. The Active Power Filter provides the Harmonic mitigation and improves the shape of input supply wave.

This method describes the simulation of a controller that uses instantaneous power theory along with PI controller for SAPF. In this process the source voltage(s) and current(s) has been used for instantaneous power calculation to generate reference currents. The reduction in dc capacitor ripple voltage of PWM-VSI inverter by using Proportional Integrated controller [6, 7] and hysteresis-band current controller has been employed for generating the switching signals for the Active Power Filter.

The SAPF is investigated under different steady state and transient conditions and found to be effective for harmonics compensation.

\section{INSTANTANEOUS POWER THEORY $[9,10]$}

This $\mathrm{p}-\mathrm{q}$ theory is based on time-domain; it is useful for steady-state or transient state. Another important characteristic of this theory is the simplicity of the calculations, which involves only algebraic calculation. In $p-q$ theory we perform a Clarke transformation of a stationary reference system of coordinate's $x-y-z$ to a reference system of coordinates $\alpha-\beta-0$ that is also stationary. In $x-y-z$ coordinates axes are fixed on the same plane, separated from each other by 120o, as shown in Figure-1.

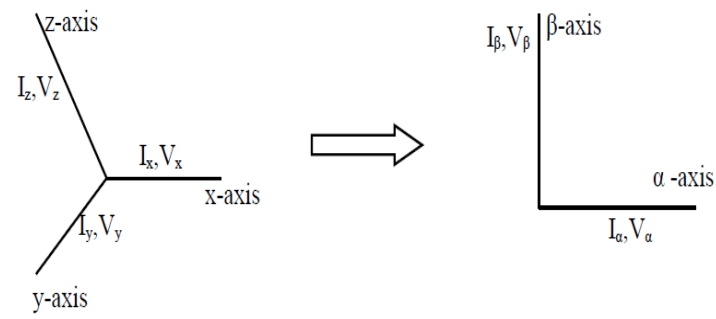

Figure-1 
The instantaneous space vectors, $\mathrm{Vx}$ and ix are set on the $\mathrm{x}$-axis, $\mathrm{Vy}$ and iy are on the $\mathrm{y}$ axis, and $\mathrm{Vz}$ and $\mathrm{iz}$ are on the $\mathrm{z}$-axis. These space vectors are easily transformed into $\alpha-\beta$ coordinates as follows:

$$
\begin{aligned}
& \left(\begin{array}{l}
V_{\alpha} \\
V_{\beta}
\end{array}\right)=\sqrt{\frac{2}{3}}\left(\begin{array}{rrr}
1 & -\frac{1}{2} & -\frac{1}{2} \\
0 & \frac{\sqrt{3}}{2} & -\frac{\sqrt{3}}{2}
\end{array}\right)\left(\begin{array}{l}
V_{x} \\
V_{y} \\
V_{z}
\end{array}\right) \\
& \left(\begin{array}{l}
I_{\alpha} \\
I_{\beta}
\end{array}\right)=\sqrt{\frac{2}{3}}\left(\begin{array}{rrr}
1 & -\frac{1}{2} & -\frac{1}{2} \\
0 & \frac{\sqrt{3}}{2} & -\frac{\sqrt{3}}{2}
\end{array}\right)\left(\begin{array}{l}
I_{x} \\
I_{y} \\
I_{z}
\end{array}\right)
\end{aligned}
$$

Where $\alpha$ and $\beta$ axes are the orthogonal coordinates $\mathrm{V} \beta$, i $\beta$ are on the $\beta$-axis and $\mathrm{V} \alpha$, i $\alpha$ are on the $\alpha$-axis.

\section{DESIGN OF SHUNT ACTIVE FILTER [3]}

Reference current signals are have been generated by applying instantaneous reactive power theory as shown in figure-2. The simulink model of proposed shunt Active Power Filter is as shown in figure-3. It has mainly has three parts, PWM voltage source inverter connected to a dc capacitor. Reduction in current harmonics is achieved by injecting equal but opposite current harmonics at the PCC (point of common coupling).This process will cancel the original distortion and improving the power quality of the connected power system.

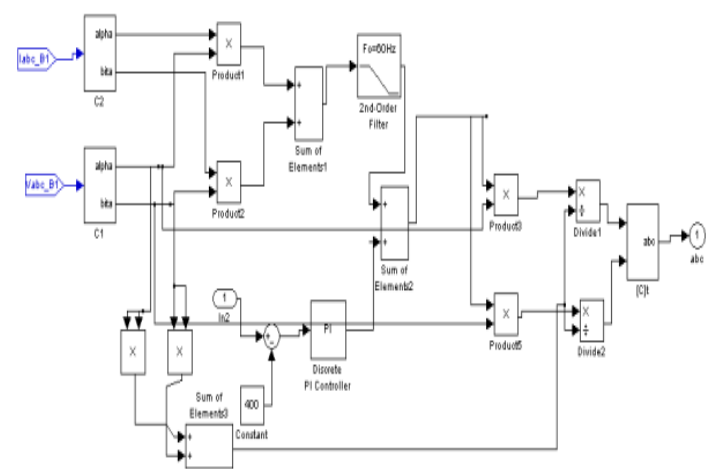

Figure-2(Reference current generation circuit)

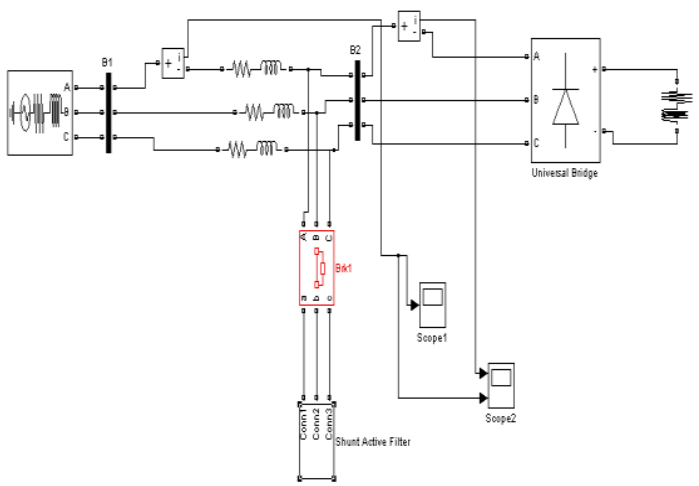

Figure-3(Design of Shunt Active Power Filter)

\section{PWM INVERTER [7]}

The active filter is based on a PWM voltage source inverter is connected to the PCC through interface filter; the active filter is connected in parallel with the AC/DC converter. This inverter uses dc capacitor as supply and can switch at high frequency to generate the current that will cancel the harmonics from AC/DC converter. The current waveform for canceling harmonics is achieved by using VSI in the current controlled mode and the interface filter. This interface filter provides smoothing and isolation for high frequency components. The desired currents are obtained by accurately controlling the switching of the MOSFET inverter. We can Control the wave shape of current by limiting the switching frequency of the inverter and by the available driving voltage across the interfacing inductance.

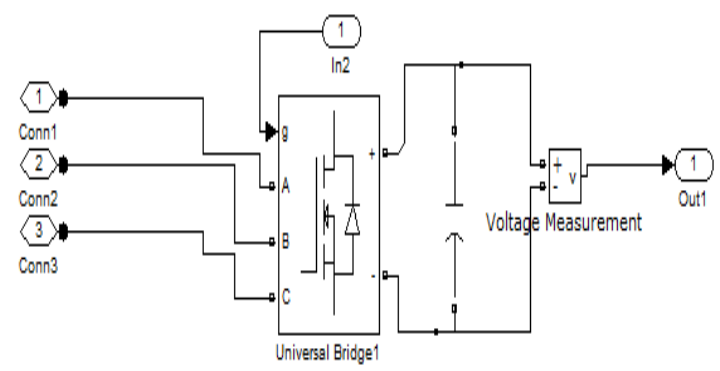

Figure-4(PWM Inverter)

\section{HYSTERESIS BAND CURRENT CONTROL [3]}

Hysteresis current control is the easiest techniques to implement; this is developed by Brod and Novotny in 1985.One disadvantage of this technique is that there is no limit on switching frequency. An additional circuitry is required to limit the maximum switching frequency. An error signal $\mathrm{E}(t)$ is used to control the switches of the inverter. When the error reaches at upper limit, the transistors are switched to force the current down. When the error reaches at lower limit the current is forced to increase. The maximum and minimum values of the error signal are Emax and Emin respectively. The range of the error signal, Emax Emin, controls the amount of ripple in the output current from the inverter.

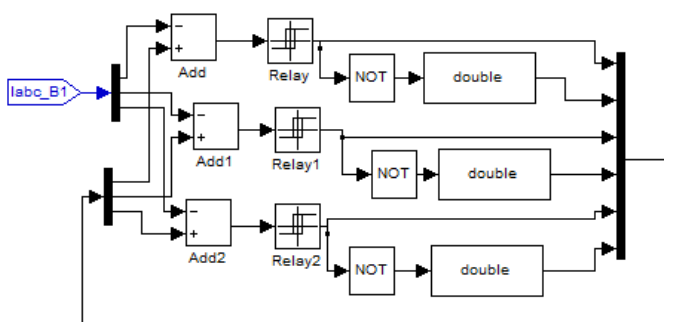

Figure-5(Hysteresis current control) 


\section{SIMULATION RESULT AND ANALYSIS}

The system parameters values are; source voltage (Vs) is $400 \mathrm{Vrms}$, System frequency (f) is $50 \mathrm{~Hz}$, Source impedance RS, LS is $0.5 \Omega, 1 \mathrm{mH}$ respectively, Filter impedance of Rc, Lc is $1 \Omega$, $1.77 \mathrm{mH}$, Load impedance RL, LL of diode rectifier are $20 \Omega, 200 \mathrm{mH}$, DC link capacitance (CDC) is $1700 \mu \mathrm{F}$, Reference Voltage (VDC) is 400 $\mathrm{V}$ and Power devices are MOSFET with an anti parallel diode.

\begin{tabular}{|c|c|c|}
\hline & $\begin{array}{c}\text { THD(Tran } \\
\text { sient State) }\end{array}$ & $\begin{array}{c}\text { THD (Steady } \\
\text { State) }\end{array}$ \\
\hline $\begin{array}{c}\text { Source Current(Is) } \\
\text { without Active } \\
\text { power filter }\end{array}$ & $23.27 \%$ & $23.10 \%$ \\
\hline $\begin{array}{c}\text { Source Current(Is) } \\
\text { with Active power } \\
\text { filter }\end{array}$ & $2.39 \%$ & $1.10 \%$ \\
\hline \multicolumn{2}{|c|}{} \\
\hline
\end{tabular}

Instantaneous power theory with PIcontrolled APLC comprises a three-phase source, a nonlinear load (six pulse diode Rectifier RL load) and a PWM voltage source inverter with a dc capacitor input. The simulation time is from $\mathrm{T}=0$ to $\mathrm{T}=10 \mathrm{~s}$ and the source current after compensation is presented in figure 7(waveform-1) that indicates the current becomes sinusoidal. The load current is shown in figure 7(waveform-2). These current waveforms are for a particular phase (phase a). We are not showing all the Phase currents because their waveforms are same but only phase shifted by 120o .Here we only consider the Balanced Load .In this proposed controller APLC supplies the compensation current. We can see that before Appling APLC source current and load current wave forms are same (Figure-6) with THD of 23.27 in transient stage and $23.1 \%$ in Study state. In Figure-7 it is clear that after Appling APLC the source current become sinusoidal.

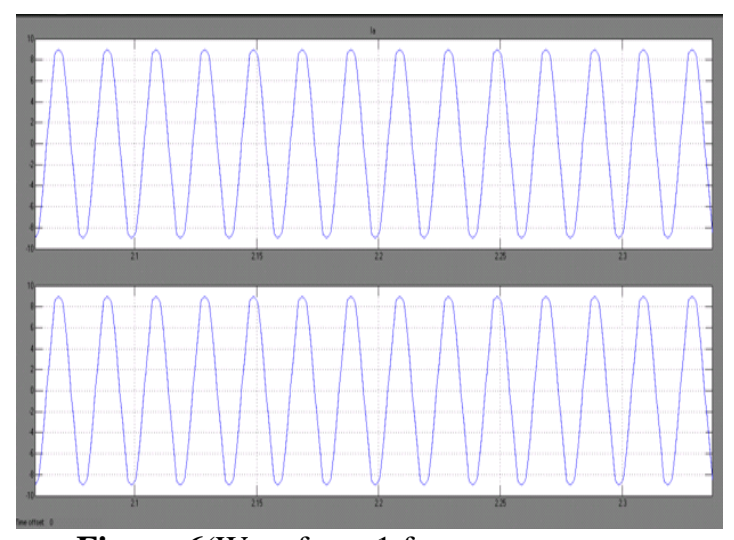

Figure-6(Waveform-1 for source current, Waveform-2 for Load current before applying active filter)

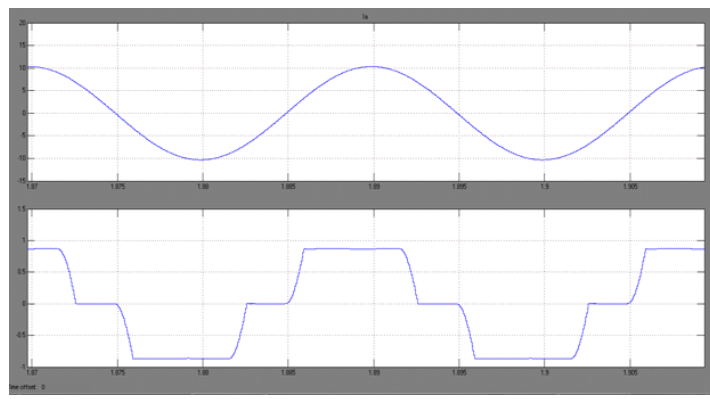

Figure-7(Waveform-1 for source current, Waveform-2 for Load current after applying active filter)

FFT analysis without Appling APLC shows that the THD is $23.10 \%$ at source side (Figure-8 \& figure-9). After Appling APLC, FFT analysis shows that THD of the source current becomes $2.39 \%$ in Transient state and $1.10 \%$ in Steady state (Figure-10 to figure-13)

\section{FFT Analysis:}

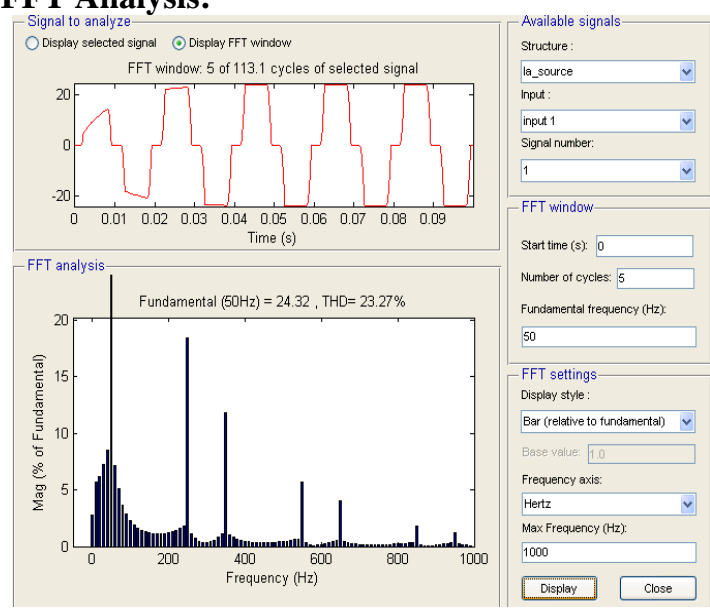

Figure-8(FFT analysis for source current before applying Active filter in Transient State $(\mathrm{THD}=23.27 \%)$ )

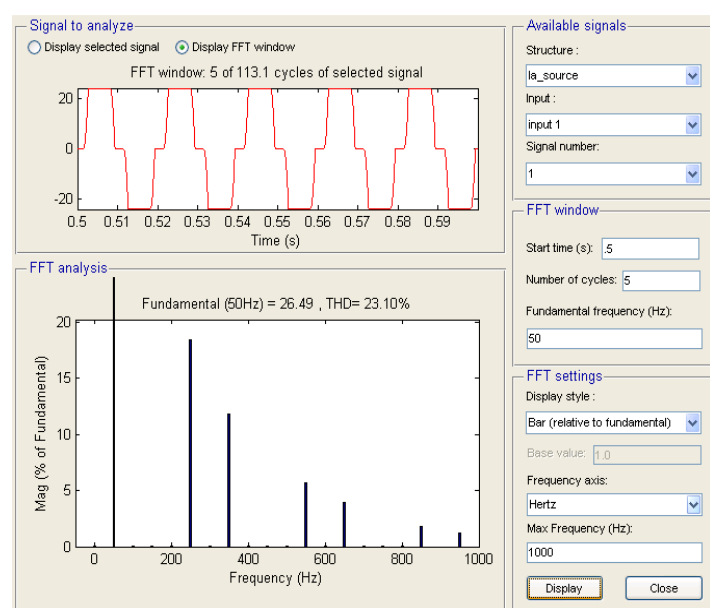

Figure-9(FFT analysis for source current before applying Active filter in Steady State $(\mathrm{THD}=23.10 \%)$ ) 

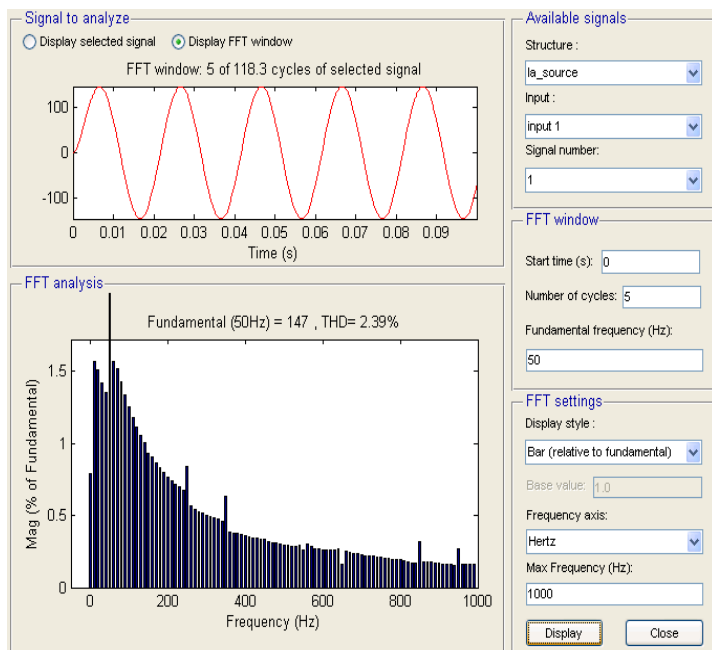

Figure-10(FFT analysis for source Current after applying of Active filter in Transient State

$(\mathrm{THD}=2.39 \%)$ )

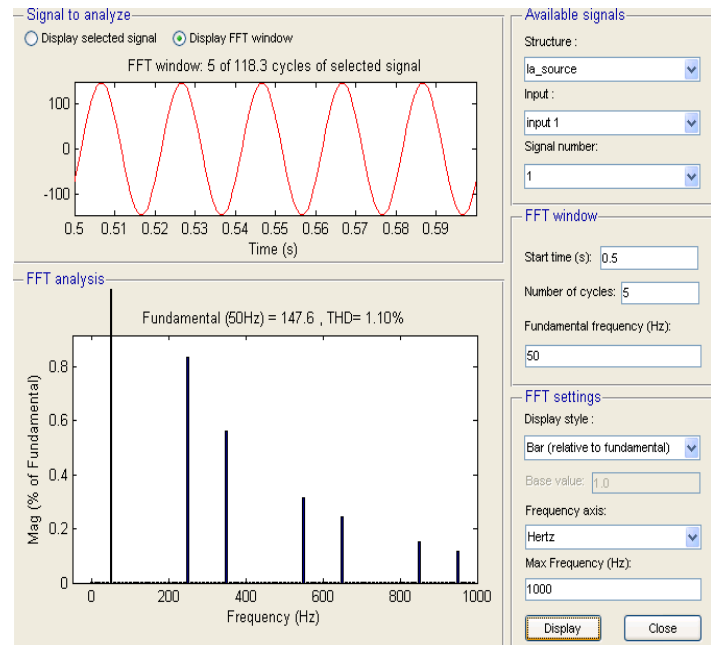

Figure-11(FFT analysis for source Current after applying of Active filter in Steady State

$(\mathrm{THD}=1.10 \%)$ )

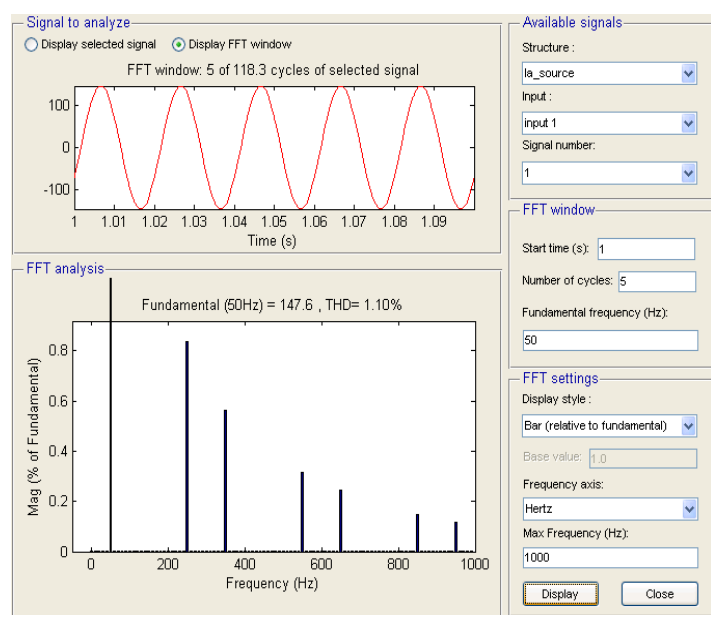

Figure-12(FFT analysis for source Current after applying of Active filter in Steady State

$(\mathrm{THD}=1.10 \%))$

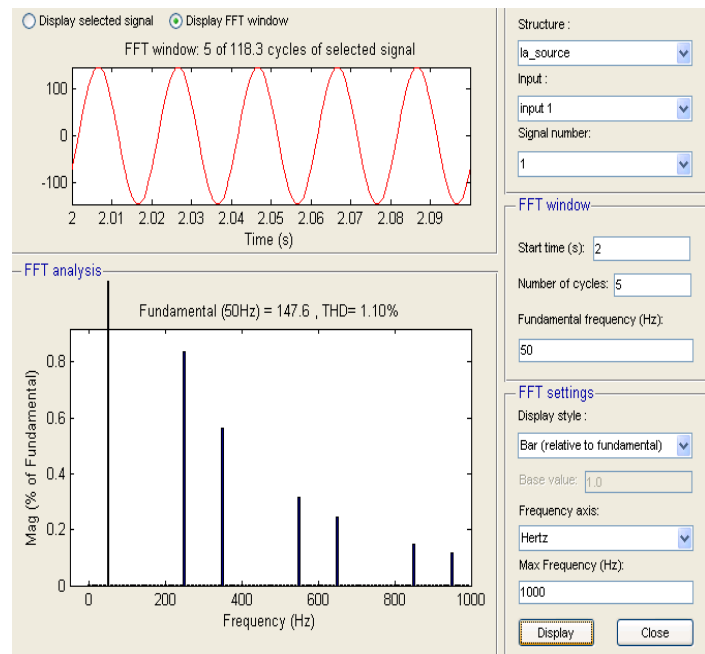

Figure-13(FFT analysis for source Current after applying of Active filter in Steady State

$(\mathrm{THD}=1.10 \%))$

\section{CONCLUSION}

A Shunt Active Power line conditioner (APLC) that uses instantaneous $\mathrm{p}-\mathrm{q}$ power theory along with PI controller is found to be an effective solution for power line conditioning. Shunt APLC with our proposed controller reduces harmonics and reactive power components of load currents; as a result sinusoidal source current(s) is achieved. The proposed Shunt Active Power line conditioner uses reduced number of sensors and less computation for reference current calculations compared to conventional approach.

The THD of the source current after compensation is $2.39 \%$ in transient state \& $1.10 \%$ in steady state after compensation, which is less than $5 \%$, the harmonic limit imposed by the IEEE519 standard.

\section{REFERENCES}

[1]. An LUO, Qianming XU, Fujun MA, Yandong CHEN "Overview of power quality analysis and control technology for the smart grid" J. Mod. Power Syst. Clean Energy (2016) 4(1):1-9

[2]. Parithimar kalaignan, Sree Renga Raja. "Harmonic Elimination By Shunt Active Filter Using PI Controller" 978-1-42445967-4/10/\$26.00 @2010 IEEE.

[3]. Karuppanan $\mathrm{P}$ and Kamal Kanta Mahapatra "PI with Instantaneous Power theory based shunt APLC for power quality" National conference on Emerging technological Trends (NCETT-2010).

[4]. V. F. Corasaniti, M. B. Barbieri,,P. L. Arnera, and M. I. Valla, "Comparison of Active Filters Topologies in Medium Voltage Distribution Power Systems" (C)2008 IEEE. 
[5]. E. H. Watanabe, H. Akagi, M. Aredes "Instantaneous p-q Power Theory for Compensating Non sinusoidal Systems "International School on Non-sinusoidal Currents and Compensation Lagow, Poland-2008.

[6]. Leszek S. Czarnecki "Instantaneous Reactive Power p-q Theory and Power Properties of Three-Phase Systems"- IEEE Trans on Power, VOL. 21, NO. 1, pp 362367, 2006.

[7]. Sato, Y., Ishizuka, T., Nezu, K. and Kataoka, T., "A new control strategy for voltage-type PWM rectifiers to realize zero steady-state control error in input current", IEEE Transactions on Industry Applications, 34 (3), 480-486, 1998.

[8]. Fang Zheng Peng "Application issues of Active Power Filter" IEEE Industry Applications Magazine September/October 1998

[9]. Fang Zheng Peng \& Jih-Sheng Lai, "Generalized Instantaneous Reactive Power Theory for Three-Phase Power Systems", IEEE Trans. on Instrument and Measurement 1996.

[10]. E. H. Watanabe, R. M. Stephan, M. Aredes, "New Concepts of Instantaneous Active and Reactive Powers in Electrical Systems with Generic Loads"- IEEE Trans. Power Delivery 1993.

[11]. Hirofumi Akagi, Yoshihira Kanazawa, Akira Nabae "Instantaneous Reactive Power Compensators Comprising Switching Devices without Energy Storage Components"- IEEE Trans on Industry Appl, 1984.

[12]. H. Akagi, Y. Kanazawa, and A. Nabae, "Generalized theory of the instantaneous reactive power in three-phase circuits," in Proc. JIEE IPEC-Tokyo, 1983.

[13]. L. Gyugyi, E. C. Strycula, "Active AC Power Filters"-in Proc. IEEE/IAS Аnпи. Meeting, 1976. 